\title{
Knowledge, attitudes and intended behaviours towards HIV testing and self-protection: a survey of Omani pregnant women
}

A.A. Al-Jabri, ${ }^{7}$ R.M. Youssef, ${ }^{2}$ S.S. Hasson, ${ }^{1}$ A.A. Balkhair, ${ }^{3}$ M. Al-Belushi, ${ }^{1}$ M. Al-Saadoon, ${ }^{4}$ M. Mathew, ${ }^{5}$ S. AlMahroqi, ${ }^{1}$ E. Said, ${ }^{1}$ C.Y. Koh ${ }^{7}$ and M.A. Idris ${ }^{1}$

$$
\begin{aligned}
& \text { المعرفة بفيروس العَوزَ المناعي البشري، والمو اقف منه، والسلو كيات التي يُنَوى اتخاذها تجاهه، والحماية الذاتية منه: مسح لنساء حو امل في عُمان }
\end{aligned}
$$

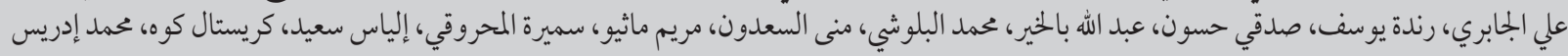

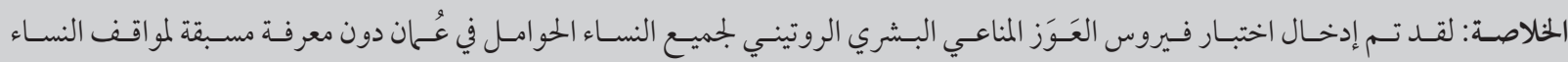

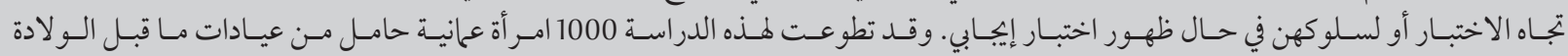

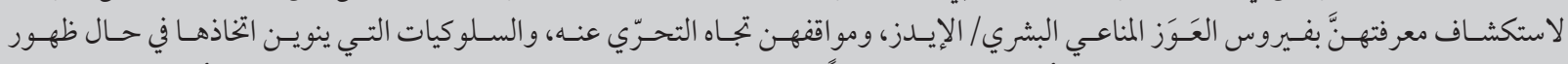

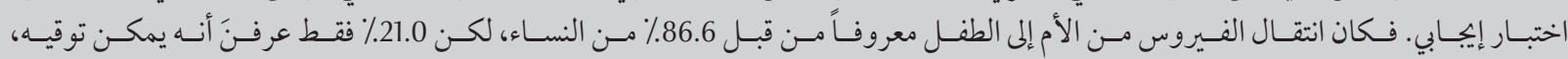

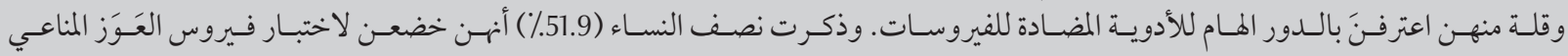

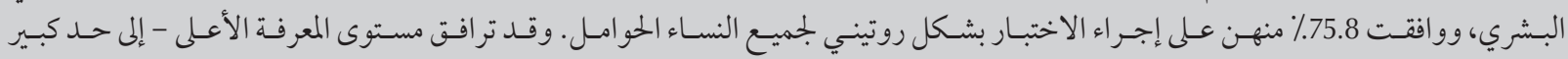

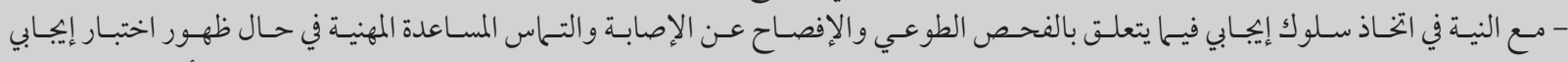

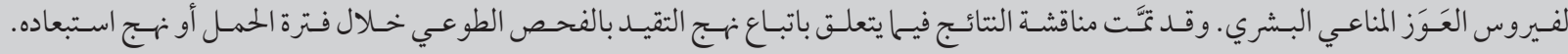

ABSTRACT Routine HIV testing of all pregnant women in Oman has been introduced without prior knowledge of women's attitudes towards testing or their behaviour in the event of a positive test. This study recruited 1000 Omani pregnant women from antenatal clinics to explore their knowledge of HIV/AIDS, attitudes towards HIV testing and intended behaviours in the event of a positive test. Mother-to-child transmission was recognized by $86.6 \%$ of the women but only $21.0 \%$ knew that it was preventable and a few acknowledged the important role of antiviral drugs. Half of the women (51.9\%) reported having been tested for HIV and 75.8\% agreed about routine HIV testing for all pregnant women. A higher level of knowledge was significantly associated with a favourable intended behaviour related to voluntary testing, disclosure and seeking professional assistance in the event of a positive HIV test. The results are discussed in relation to opt-in and opt-out approaches to voluntary testing during pregnancy.

\section{Connaissances, attitudes et comportements souhaités concernant le dépistage du VIH et l'autoprotection : une enquête auprès de femmes enceintes omanaises}

RÉSUMÉ Le dépistage systématique du VIH chez toutes les femmes enceintes a été introduit à Oman avant de connaitre l'attitude des femmes vis-à-vis du dépistage ou leur comportement dans le cas où leur test serait positif. L'étude a recruté 1000 femmes enceintes omanaises dans des cliniques prénatales, afin d'analyser leur niveau de connaissances sur le VIH/sida, leurs attitudes vis-à-vis du dépistage du VIH et les comportements souhaités en cas de test positif. La transmission de la mère à l'enfant était reconnue par $86,6 \%$ des femmes mais seulement $21,0 \%$ savaient qu'elle était évitable, tandis que quelques-unes connaissaient le rôle important des médicaments antirétroviraux. La moitié des femmes (51,9\%) ont déclaré avoir déjà effectué un test de dépistage du VIH et 75,8 \% étaient en faveur du dépistage systématique du VIH chez toutes les femmes enceintes. Un niveau de connaissances élevé était significativement associé à un comportement souhaité favorable en ce qui concerne le dépistage volontaire, la communication des résultats et la recherche d'une assistance professionnelle dans le cas d'un résultat positif. Les résultats à l'étude sont examinés par rapport aux stratégies de dépistage avec consentement préalable explicite et avec consentement implicite dans le cadre du dépistage volontaire pendant la grossesse.

${ }^{7}$ Department of Microbiology and Immunology; ${ }^{2}$ Department of Family Medicine and Public Health; ${ }^{4}$ Department of Child Health; ${ }^{5}$ Department of Obstetrics and Gynaecology, College of Medicine and Health Sciences, Sultan Qaboos University, Muscat, Oman (Correspondence to A.A. Al-Jabri: aaljabri@squ.edu.om).3Infectious Diseases Unit, Department of Medicine, Sultan Qaboos University Hospital, Muscat, Oman.

Received: 16/09/13; accepted: 12/05/14 


\section{Introduction}

Women represent almost half of the cases of HIV/AIDS worldwide (1). The global epidemiology of HIV in children reflects that of HIV in women (2). Mother-to-child transmission is the major route of HIV infection among children and a source of almost all AIDS cases in children in many countries (3-5). Approximately $15-25 \%$ of infants of HIV infected mothers are infected during pregnancy or during delivery, and around $5-20 \%$ of them are infected during breastfeeding (6).

A current estimate of the number of people living with HIV/AIDS in Oman is lacking; however, a total of 1371 cases alive were reported as of December 2011 (7). Despite this low number of cases alive, Oman has demonstrated a commitment to the prevention ofHIV/AIDS and has succeeded in exerting maximum control on HIV transmission via blood, blood products and sharps in health-care settings. The National AIDS Control Programme in Oman has adopted a combination of strategies including public education and voluntary testing and counselling followed by the standard treatment including measures for preventing mother-to-child transmission (7). In 2005 less than $50 \%$ of women in the reproductive age group had the correct information about HIV/AIDS (8). The 2008 national survey revealed that only $2 \%$ of women attending for antenatal care opted for voluntary testing and more than $30 \%$ of women who were advised to have HIV testing refused to be tested (9). The national response strategy to HIV/AIDS was extended to the integration of HIV testing into antenatal care services in 2009 at a cost of US \$2.5 million, which was viewed as a critical step in halting the spread of AIDS (7). Such an approach resulted in the testing of $99.4 \%$ of the women attending for antenatal care between January 2010 and December 2011 (7). A positive HIV result in a woman warrants the initiation of antiretroviral therapy for long-term treatment and interruption of transmission of HIV infections to infants and young children (2).

Public health policies aimed at the protection of women and their children from HIV infection requires understanding of women's awareness of the risks and the available interventions that enable them to make informed choices. Routine testing of all pregnant women in Oman has been introduced without prior knowledge of women's attitudes towards testing and their intended behaviours in the event of a positive test. It has also raised ethical concerns regarding the violation of women's right to opt out of testing. This study of Omani pregnant women aimed to investigate their knowledge about HIV/AIDS, attitudes towards HIV testing and intended behaviours if HIV/AIDS were suspected or confirmed.

\section{Methods}

\section{Study design and sample}

A cross-section survey targeting Omani pregnant women was conducted between 2011 and 2012 in 8 out of the 11 administrative regions with the largest population sizes.

The sample size was estimated using the open-access Epi-Info program (10), based on the number of women of reproductive age (15-49 years; $N$ $=600868$ ), as per 2010 population estimates (11). To obtain the largest sample size, it was assumed that $50 \%$ of women have knowledge of motherto-child transmission with a chosen $5 \%$ degree of precision, a design effect of 2.5 to compensate for complex sampling and $95 \%$ level of confidence. The estimated minimum sample size was 960 women and was allocated proportional to the size of the target population in each region. As coverage with antenatal care services in Oman is 99\% (9), women were recruited from antenatal care clinics in the main 20 hospitals and health centres in these regions. Health-care facilities were visited daily and all eligible women were recruited until the desired sample size was reached.

Ethical clearance was obtained from the ethics committee of the College of Medicine and Health Sciences, Sultan Qaboos University. Women were briefed about the purpose of the study and requested to sign an informed consent. Refusal and non-response were not reported. At the end of the interview participants were provided with a specially designed educational leaflet about HIV/ AIDS counselling and testing.

\section{Data collection}

Data were collected by a trained female researcher using a predesigned and pretested questionnaire interview with closed-ended responses. The collected data included: the woman's attributes (including age, education attainment, employment and family income); attitude towards testing for HIV; knowledge about groups at high risk of infection (including people who inject drugs, sex workers and women having sex with an infected partner); knowledge about routes of HIV transmission and the manifestations of AIDS; and intended behaviour in the event of discovering a probable or actual infection of her husband and of herself.

A total of 16 questions were used to determine women's knowledge about HIV transmission (9 questions) and AIDS manifestations (7 questions). Each question had 3 responses: yes, no and uncertain. A knowledge scale was developed after testing for internal consistency ( $\alpha=$ 0.75 ) by assigning a score of 1 for each correct response and a score of 0 for each incorrect or uncertain response. 
The total scores were computed by summing the score of the 16 questions and were expressed as percentages of the maximum scores.

\section{Data analysis}

The data were analysed using SPSS, version 19 , and presented as percentages as well as mean and standard error (SE) of the mean. The Student $t$-test and 1-way analysis of variance (F-test) were used for testing the significance of the results at the $5 \%$ level.

\section{Results}

\section{Women's attributes}

The study included 1000 Omani women between the age of 18 and 48 years [mean age 28.9 (SE 5.14) years]. A few women were illiterate (1.1\%) or just able to read and write (1.8\%) while the majority had received school education (51.1\%), a diploma certificate $(22.5 \%)$ or a university or higher degree (23.5\%). At the time of the survey, $49.9 \%$ were housewives while the remaining women were employed in the government (43.1\%) or private sectors $(5.4 \%)$ or were selfemployed (1.6\%).

Nearly half of the women (44.8\%) had been married for more than 5 years and $41.3 \%$ had 3 or more children. The majority of the women (90.0\%) were living with their husbands and only $12.5 \%$ reported that their husbands frequently travelled. Based on family income, more than three-quarters of the women reported an average (52.3\%) or above average (27.3\%) family income while $2.2 \%$ reported high or very high income.

\section{Knowledge about HIV/AIDS}

Almost all of the women (95.5\%) had heard about HIV/AIDS. The main sources of HIV/AIDS information were at school during their school years $(37.8 \%)$ and the mass media (33.9\%). The remaining proportion of women $(28.3 \%)$ had acquired their knowledge about AIDS from their social network.

Almost all the women had correct knowledge about the possibility of acquiring HIV infection by sexual contact (97.1\%), blood transfusion (95.9\%) and contaminated syringes (91.4\%). However, a proportion of women reported that the disease is transmitted by kissing (40.0\%), casual contact such as hugging and handshakes $(26.4 \%)$ and sharing food and drinks (19.4\%) (Table 1).

Table 1 reveals that $86.6 \%$ of the women knew that HIV can be transmitted from the mother to the fetus, either prior to delivery (42.0\%), during delivery $(19.2 \%)$ or prior and during delivery (27.8\%). Only $21.0 \%$ $(n=181)$ of these women knew that

\begin{tabular}{|c|c|c|c|c|c|c|}
\hline \multirow[t]{2}{*}{ Women's knowledge } & \multicolumn{2}{|c|}{ Yes } & \multicolumn{2}{|c|}{ No } & \multicolumn{2}{|c|}{ Uncertain } \\
\hline & No. & $\%$ & No. & $\%$ & No. & $\%$ \\
\hline \multicolumn{7}{|l|}{ Mode of transmission } \\
\hline Sexual contact & 971 & 97.1 & 12 & 1.2 & 17 & 1.7 \\
\hline Blood transfusion & 959 & 95.9 & 10 & 1.0 & 31 & 3.1 \\
\hline Contaminated syringes & 914 & 91.4 & 18 & 1.8 & 68 & 6.8 \\
\hline Mother to fetus & 866 & 86.6 & 38 & 3.8 & 96 & 9.6 \\
\hline Breastmilk & 459 & 45.9 & 214 & 21.4 & 327 & 32.7 \\
\hline Kissing & 400 & 40.0 & 408 & 40.8 & 192 & 19.2 \\
\hline Casual contact & 264 & 26.4 & 657 & 65.7 & 79 & 7.9 \\
\hline Kissing of infants & 224 & 22.4 & 548 & 54.8 & 228 & 22.8 \\
\hline Food and drinks & 194 & 19.4 & 727 & 72.7 & 81 & 8.1 \\
\hline \multicolumn{7}{|l|}{ Population group at risk } \\
\hline People who inject drugs and sex workers are at risk & 866 & 86.6 & 41 & 4.1 & 93 & 9.3 \\
\hline Woman is infected if husband is infected & 514 & 51.4 & 348 & 34.8 & 138 & 13.8 \\
\hline \multicolumn{7}{|l|}{ Manifestation of AIDS } \\
\hline Impaired immunity & 850 & 85.0 & 11 & 1.1 & 139 & 13.9 \\
\hline Weakness/lethargy & 793 & 79.3 & 16 & 1.6 & 191 & 19.1 \\
\hline Weight loss & 703 & 70.3 & 46 & 4.6 & 251 & 25.1 \\
\hline Frequent skin eruption/blisters & 636 & 63.6 & 56 & 5.6 & 308 & 30.8 \\
\hline Herpetic eruptions & 467 & 46.7 & 50 & 5.0 & 483 & 48.3 \\
\hline Chronic diarrhoea & 453 & 45.3 & 88 & 8.8 & 459 & 45.9 \\
\hline Chronic cough & 359 & 35.9 & 119 & 11.9 & 522 & 52.2 \\
\hline
\end{tabular}


mother-to-child transmission is preventable and less than half of the latter $(n=82 ; 45.3 \%)$ knew that HIV transmission can be prevented by antiviral drugs. Less than half (45.9\%) reported that HIV can be transmitted from the mother to the infant through breastmilk and $22.4 \%$ reported that HIV can be transmitted from the mother to the infant through kissing.

The majority of the women (86.6\%) recognized that sex workers and people who inject drugs are at high risk of contracting HIV and $51.4 \%$ stated that a woman can be infected if her husband were infected (Table 1).

More than two-thirds of the women (68.7\%) knew that HIV/AIDS could not be recognized simply by looking at a person. High proportions of the women also knew that HIV/ AIDS is manifested by impaired immunity (85.0\%), weakness and lethargy (79.3\%), loss of weight (70.3\%) and frequent skin eruptions (63.6\%).
Less frequently recognized manifestations of HIV/AIDS were herpetic skin eruptions (46.7\%), chronic diarrhoea $(45.3 \%)$ and chronic cough (35.9\%) (Table 1).

A proportion of women had no knowledge about the time elapsed between HIV infection and the development of AIDS (41.5\%) and the outcome of the disease (24.5\%). The remaining proportions estimated that the development of AIDS is within 1 year $(9.9 \%)$, between $1-5$ years (21.2\%) and between 5-10 years (21.0\%) after the initial infection. Only $6.4 \%$ stated that AIDS can occur more than 10 years after the initial infection with HIV. In respect to the outcome of the disease, $36.1 \%$ of the women reported that there is no available treatment and $39.4 \%$ stated that AIDS has no cure.

The mean of score of women on the HIV/AIDS knowledge scale was 65.0\% (SE 0.6). Their level of knowledge about the transmission of HIV
[72.3\% (SE 0.6)] was higher than that of AIDS manifestations [ 57.4\% (SE 0.9]. Table 2 shows the mean scores of women's combined knowledge of HIV transmission and AIDS manifestations in relation to their attributes. Significantly higher scores were found among women who had received a diploma, a university or postgraduate degree $(P<0.001)$ and those who were ever employed $(P<0.001)$. Significantly higher scores were also observed among women who rated their income as above average or high $(P=0.001)$. No significant differences in the mean scores were observed in relation to women's age $(P=0.173)$ or duration of marriage $(P=0.971)$.

\section{Testing for HIV}

More than half of the women in this study (51.9\%) reported that they had been tested for HIV and 36.0\% of those who had not been tested expressed a desire to know their HIV status. A favourable response towards

\begin{tabular}{|c|c|c|c|c|}
\hline Women's characteristics & No. of respondents & Mean score (SE) & Median score & $P$-value \\
\hline \multicolumn{5}{|l|}{ Age (years) } \\
\hline$<25$ & 197 & $64.0(1.3)$ & 65.9 & \multirow[t]{3}{*}{0.173} \\
\hline $25-<35$ & 658 & $65.7(0.8)$ & 69.8 & \\
\hline$\geq 35$ & 145 & $62.5(1.7)$ & 65.9 & \\
\hline \multicolumn{5}{|l|}{ Duration of marriage (years) } \\
\hline$<2$ & 243 & $65.0(1.2)$ & 67.5 & \multirow[t]{3}{*}{0.971} \\
\hline $2-5$ & 309 & $65.1(1.1)$ & 69.1 & \\
\hline$>5$ & 448 & $64.7(1.0)$ & 68.3 & \\
\hline \multicolumn{5}{|l|}{ Family income } \\
\hline Low/below average & 182 & $60.4(1.5)$ & 63.5 & \multirow[t]{3}{*}{0.001} \\
\hline Average & 523 & $63.8(0.9)$ & 67.5 & \\
\hline Above average/high & 295 & $69.5(1.0)$ & 73.0 & \\
\hline \multicolumn{5}{|l|}{ Education } \\
\hline Never been to school & 29 & $54.1(3.9)$ & 56.4 & \multirow[t]{3}{*}{0.001} \\
\hline School education & 511 & $59.1(0.9)$ & 61.9 & \\
\hline Diploma/university degree & 460 & $72.0(0.7)$ & 74.6 & \\
\hline \multicolumn{5}{|l|}{ Employment } \\
\hline Employed & 518 & $66.9(0.8)$ & 70.6 & \multirow[t]{2}{*}{0.001} \\
\hline Unemployed & 482 & $62.7(1.0)$ & 67.5 & \\
\hline
\end{tabular}

$S E=$ standard error of the mean. 


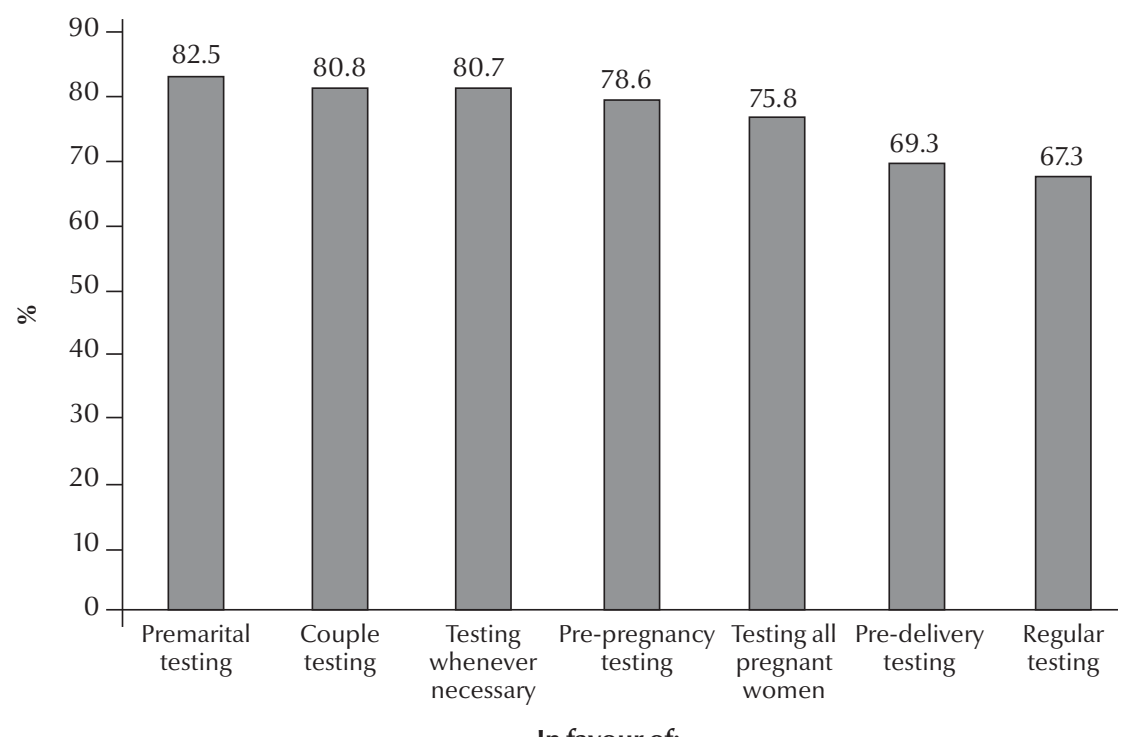

In favour of:

Figure 1 Women's attitudes towards testing for HIV $(n=1000)$

routine testing for HIV was given by $75.8 \%$ of the women, and $80.7 \%$ agreed that testing for HIV should be considered whenever necessary. Between $75.0 \%$ and $82.5 \%$ of women agreed with premarital testing, couple testing, pre-pregnancy testing and testing of all pregnant women. Lower proportions of women agreed with pre-delivery testing (69.3\%) and regular and continuous testing (67.3\%) (Figure 1)

The majority of women (91.6\%) had a preference regarding the protocol for testing for HIV. The preference of $62.5 \%$ of these women was for voluntary testing while the preference of the remaining proportion was for routine testing (25.8\%) and group testing $(11.7 \%)$.

\section{Attitudes and intended behaviours}

Table 3 shows women's attitudes towards testing and intended behaviours in the event of a probable or actual infection of their husbands with $\mathrm{HIV}$, in relation to their knowledge scores. In the event of a suspected infection of the husband, the intention of $93.0 \%$ of women would be to go for couple testing, while $51.2 \%$ would seek testing alone. In reference to marital relations, $65.9 \%$ of the women would ask their husband to use a condom and only $15.7 \%$ said they would maintain sexual relations with their husbands. The intention of $43.1 \%$ of the women was to remain in the marriage. Willingness to disclose the event was expressed by $80.0 \%$ of the women. In the event of actual infection of the husband, $91.0 \%$ of the women agreed that they would seek medical assistance. Lower proportions would seek psychotherapy (63.1\%) or assistance from people in their social network (53.5\%). The intention of $50.0 \%$ of the women was to continue their pregnancy. Table 3 shows that the mean knowledge score was significantly higher among women who agreed with routine testing of all pregnant women and those who expressed favourable intended behaviours in the event of probable or actual infection of the husband.

In the event that the woman herself was HIV-infected, the intention of a large proportion of the Omani women was to consult a physician (88.8\%) and to disclose their status to their husbands (86.5\%). Lower proportions would disclose their status to their relatives $(60.1 \%)$ or others in their social network (21.8\%). The intention of $71.0 \%$ of the women was to discontinue breastfeeding and $88.1 \%$ said that they would not have more children. Significantly higher scores on knowledge of transmission and manifestations of HIV were observed among women who expressed an intention to inform their husbands $(P<0.001)$, discuss their status with the physician $(P<0.001)$, discontinue breastfeeding $(P=0.015)$ and not have any more children $(P<0.001)$. The knowledge scores of women who would disclose and discuss their HIV status with relatives and others in their social network was not significantly higher than those who did not express the same intention (Table 3).

\section{Discussion}

This study focused on women of reproductive age because of their vulnerability to HIV/AIDS. The Global AIDS Response Progress report for Oman for the year 2012 revealed that half of the HIV/AIDS cases among Omanis were acquired through heterosexual transmission and that woman represented $28.8 \%$ of the cases (7). In this respect, we can expect that women will play a pivotal role in protecting themselves and their unborn children, provided they have the knowledge and means to prevent infection (1).

The mean overall score on the knowledge scale (65.0\%) reflects an unsatisfactory level of knowledge among women of reproductive age in Oman. However women's level of knowledge about modes of transmission of HIV was higher than their level of knowledge of AIDS manifestations. In fact, more than $90 \%$ of women had knowledge about transmission of HIV by sexual contact, intravenous injection of illicit drugs and blood transfusion. This was expected, as there have 


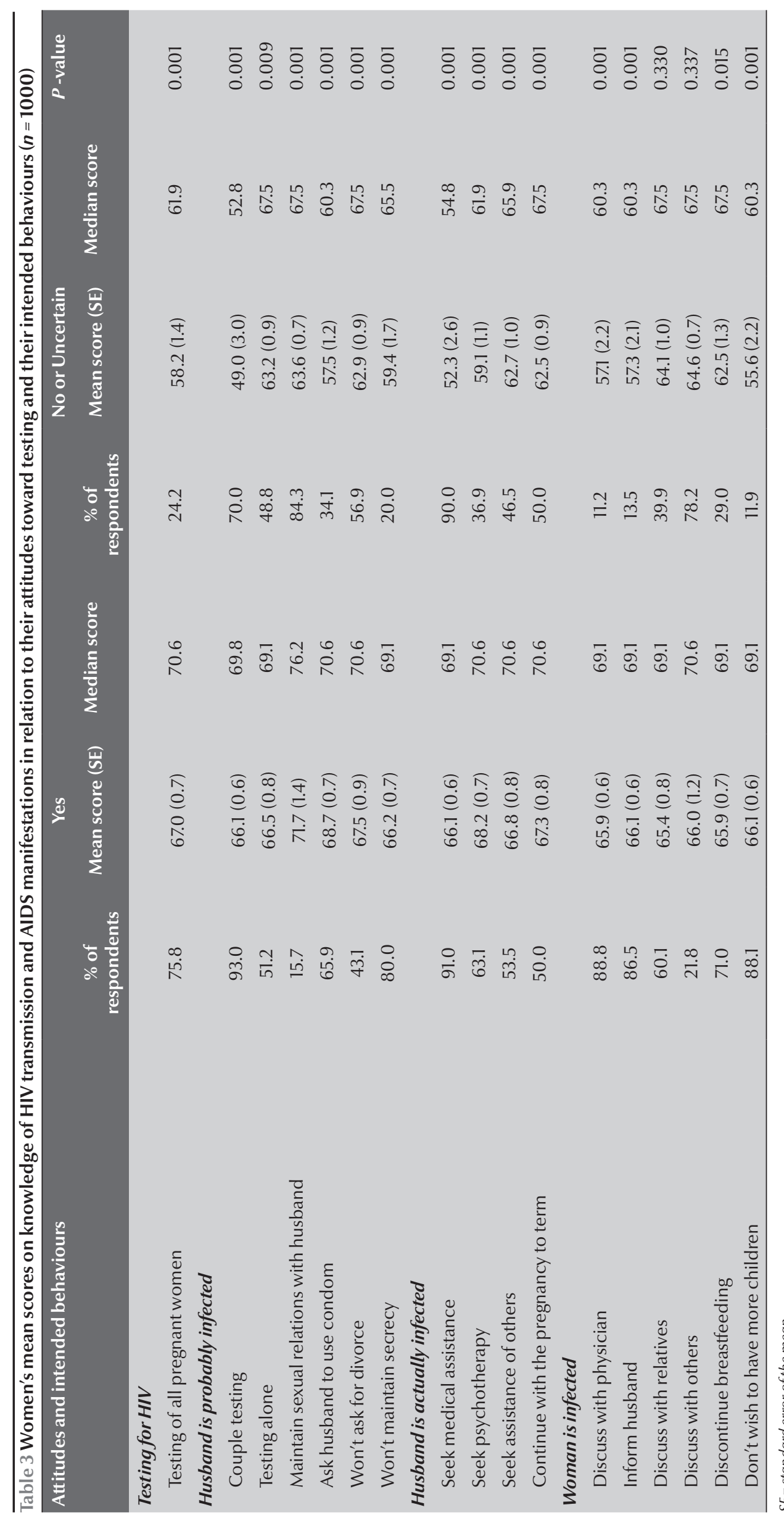


been educational campaigns across Oman to raise public awareness about the means of HIV/AIDS prevention and these have emphasized risky behaviours and modes of transmission. A higher level of knowledge was noted among women belonging to the more affluent stratum of society, indicated by better education, employment and higher income. Information, education and communication activities should target less privileged women via mass media as a source of information.

In this study, $86.6 \%$ of women were aware of the vertical transmission of HIV from the mother to the child during pregnancy and labour. However, only a small proportion of these women were aware that it is preventable and few acknowledged the role of antiviral drugs in this respect. Furthermore, less than half of the women knew that the virus can be transmitted through breastfeeding. Poor knowledge in these areas has been reported among women of reproductive age in the Islamic Republic of Iran (12), Ethiopia (13) and Nigeria (14). Lack of knowledge was shown to be a barrier to women taking appropriate actions for the prevention of mother-to-child transmission, as a higher level of knowledge in this study was associated with desirable intended behaviours related to testing and maintaining healthy sexual relations. Measures such as discontinuation of breastfeeding and abstaining from having more children were reported by women with higher levels of knowledge because of their awareness of the associated risks. However, it reflects as well their lack of knowledge that this intended behaviour is not necessary if effective interventions for preventing mother-to-child transmission are introduced.

Increasing the availability and acceptability of HIV testing and counselling services will no doubt encourage more women to know their status, providing a gateway to preventing mother-to-child transmission (15). Half of the women in this study had been tested, a figure which is lower than the $99.4 \%$ reported by the Omani Ministry of Health for the period 2010-2011 (7). This discrepancy may be due to the fact that the index visit was the first for a proportion of these women and they were interviewed while waiting to be seen by their physician. Also, it is not unlikely that a proportion of women were not aware that they had been tested. Almost a third of women who were not tested expressed a willingness to know their HIV status and a substantial proportion of them expressed favourable attitudes towards premarital testing for HIV as well as testing prior to or during pregnancy. For many women, particularly in resource-poor areas, pregnancy may be the only time in their young adult lives when they have regular access to health-care services. The integration of HIV testing into antenatal services is critical for the scaling up of interventions to prevent mother-to-child transmission (16-18). Testing is an opportunity for counselling HIVnegative women about ways of protecting themselves and their infants $(15,19)$. HIV-positive women will benefit from an intervention package of antiretroviral treatment and from caesarean delivery, as well as counselling and support regarding breastfeeding options (20-22). More than a third of women in this study were not aware of the existence of medications for the treatment of HIV/AIDS, despite the fact that the currently available antiretroviral drugs have changed the picture of AIDS from a fatal and deadly disease to a manageable illness (23). The introduction of combination antiretroviral therapy early in the course of pregnancy suppresses viral replication, with subsequent reduction of perinatal transmission to less than $1 \%(4)$.
The previous recommendation of the Centers for Disease Control and Prevention for voluntary antenatal HIV testing of pregnant women has been criticised by those who advocate routine testing for preventing mother-to-child transmission (24). The universal "opting out" testing of all pregnant women has proved to be superior to the voluntary "opting in" testing and counselling in identifying more HIV-positive pregnant women and bringing them into care (25). However, Field and Kaplan (26) and Bulman et al. (27) have cautioned that the opting out approach may raise ethical concerns if women's informed consent is violated, as the increase in the rate of testing is achieved at the expense of women's knowledge that the test is optional (26) and marginalizing their right to refuse (27). Although voluntary testing was the preference of nearly two-thirds of women enrolled in this study, more than three-quarters of them accepted the routine testing of all pregnant women initiated by the Public Health Directorate at the Ministry of Health in Oman. It has been proved that the opting out approach to HIV testing is more acceptable and less stigmatizing (28). The Public Health Directorate should achieve a balance between missed preventive opportunities and violation of women's rights to refusal by intensification of educational activities targeting women of reproductive age and by providing pre-testing counselling.

Currently the global goal has shifted from prevention of motherto-child transmission to the elimination of mother-to-child transmission by 2015 (29), which is a realistic goal (5) provided effective interventions are in place (30). The infection rates among infants born to infected mothers have dropped significantly as a result of the high rates of coverage with antiretroviral prophylaxis 
(2), which range between $50 \%$ and $80 \%$ in sub-Saharan Africa and exceed $80 \%$ in Botswana, Namibia, South Africa and Swaziland (5). It is too early to determine the effect of routine HIV screening of pregnant women that was implemented in Oman in 2009.

The main limitation of this study was that it reflected women's attitudes towards testing and intended behaviour rather than their positions when providing consent for testing and their actual behaviours in the event of a positive test.

Future research in this area should focus on evaluation of the HIV programme's impact on women's knowledge and attitudes towards HIV screening as well as its outcome in terms of the number of HIV-positive women identified and the number of HIV infections prevented among infants.
Acknowledgements

We acknowledgement with thanks all the Omani women who participated in this project.

Funding: This research was supported by a grant from the College of Medicine and Health Sciences, Sultan Qaboos University, Muscat, Oman and the Research Council of the Sultanate of Oman (RC/MED/MICR/11/01).

Competing interests: None declared.

\section{References}

1. Women and HIV/AIDS: confronting the crisis. Geneva: Joint United Nations Programme on HIV/AIDS, United Nations Population Fund, United Nations Development Fund For Women; 2004 (http://www.unfpa.org/hiv/women/docs/ women_aids.pdf, accessed 8 June 2014).

2. Global report. UNAIDS report on the global AIDS epidemic 2010. Geneva: Joint United Nations Programme on HIV/ AIDS; 2010 (http://www.unaids.org/globalreport/documents/20101123_GlobalReport_full_en.pdf, accessed 8 June 2014).

3. Mofenson LM. Advances in the prevention of vertical transmission of human immunodeficiency virus. Semin Pediatr Infect Dis. 2003 Oct;14(4):295-308. PMID:14724794

4. HIV among pregnant women, infants and children in the United States. CDC HIV/AIDS Fact Sheet. December 2012. Atlanta (GA): Centers For Disease Control and Prevention; 2012 (http://www.cdc.gov/hiv/pdf/risk_WIC.pdf, accessed 8 June 2014).

5. Antiretroviral drugs for treating pregnant women and preventing HIV infection in infants: towards universal access 2010. Geneva: World Health Organization; 2010 (http://whqlibdoc. who.int/publications/2010/9789241599801_eng.pdf, accessed 8 June 2014).

6. HIV and infant feeding: a guide for health-care managers and supervisors. Geneva: World Health Organization; 2003 (http://www.unfpa.org/webdav/site/global/shared/documents/publications/2003/hiv_infant_feeding_guide.pdf, accessed 8 June 2014).

7. 2012 Global AIDS response progress report. Muscat; Ministry of Health; 2012 (http://www.unaids.org/en/dataanalysis/ knowyourresponse/countryprogressreports/2012countries/ ce_OM_Narrative_Report[1].pdf, accessed 18 June 2014).

8. The seventh 5-year plan for health and development (20062010): promoting women and child health. Muscat: Ministry of Health; 2005 (http://www.moh.gov.om/en/fiveyearplan/ English/Part_04.pdf, accessed 8 June 2014).

9. Al-Riyami A, Abd El Aty MA, Jaju S, Morsi M, Al-Kharusi H. AI-Shekaili W on behalf of the Ministry of Health, Directorate of Research and Studies. Reproductive health Survey 2008. Muscat; Ministry of Health; 2008 (http://www.moh.gov.om/ en/reports/WHS/RHS/RHS.pdf, accessed 8 June 2014).

10. Dean AG, Sullivan KM, Soe MM. OpenEpi: Open source epidemiologic statistics for public health (updated 2013) (www. openepi.com, accessed 8 June 2014).

11. 2010 Annual statistical report. Muscat: Ministry of Health; 2010 (http://www.moh.gov.om/en/stat/2010/Chapters/ CH01Y10.pdf, accessed 18 June 2014).
12. Majid T, Farhad Y, Sorour A, Soheila A, Farnaz F, Hojjat Z, et al. Preventing mother-to-child transmission of HIV/AIDS: do Iranian pregnant mothers know about it? J Reprod Infertil. 2010 Apr;11(1):53-7. PMID:23926481

13. Asefa A, Beyene $\mathrm{H}$. Awareness and knowledge on timing of mother-to-child transmission of HIV among antenatal care attending women in Southern Ethiopia: a cross sectional study. Reprod Health. 2013;10:66. 10.1186/1742-4755-10-66 PMID:24330487

14. Abiodun MO, ljaiya MA, Aboyeji PA. Awareness and knowledge of mother-to-child transmission of HIV among pregnant women. J Natl Med Assoc. 2007 Jul;99(7):758-63. PMID:17668641

15. Bolu OO, Allread V, Creek T, Stringer E, Forna F, Bulterys M, et al. Approaches for scaling up human immunodeficiency virus testing and counseling in prevention of mother-tochild human immunodeficiency virus transmission settings in resource-limited countries. Am J Obstet Gynecol. 2007 Sep;197(3) Suppl:S83-9. PMID:17825654

16. Rutenberg N, Kalibala S, Baek C, Rosen J. Programme recommendations for the prevention of mother-to-child transmission of HIV. New York (NY): United Nationals Children's Fund; 2003.

17. Sandgren E, Sandgren S, Urazalin M, Andersson R. HIV/AIDS awareness and risk behaviour among pregnant women in Semey, Kazakhstan, 2007. BMC Public Health. 2008;8:295. 10.1186/1471-2458-8-295 PMID:18721467

18. Chivonivoni C, Ehlers VJ, Roos JH. Mothers' attitudes towards using services preventing mother-to-child HIV/AIDS transmission in Zimbabwe: an interview survey. Int J Nurs Stud. 2008 Nov;45(11):1618-24. PMID:18502426

19. Prevention of HIV transmission from mother to child. Geneva: Joint United Nations Programme on HIV/AIDS; 1999.

20. Prevention of mother-to-child transmission of HIV: Use of nevirapine among women of unknown serostatus. Geneva: World Health Organization; 2001.

21. New data on the prevention of mother-to-child transmission of HIV and their policy implications. Geneva: World Health Organization; 2001.

22. Towards universal access: Scaling up priority HIV/AIDS interventions in the health sector. Geneva: World Health Organization, Joint United Nations Programme on HIV/AIDS, United Nations Children's Fund; 2010.

23. Al-Jabri AA, Alenzi FQ. Vaccines, virucides and drugs against HIV/AIDS: hopes and optimisms for the future. Open AIDS J. 2009;3:1-3. PMID:19274070 
24. Kass N. A change in approach to prenatal HIV screening. Am J Public Health. 2000 Jul;90(7):1026-7. PMID:10897175

25. Boer K, Smit C, van der Flier M, de Wolf F; ATHENA cohort study group. The comparison of the performance of two screening strategies identifying newly-diagnosed HIV during pregnancy. Eur J Public Health. 2011 Oct;21(5):632-7. PMID:21051473

26. Fields L, Kaplan C. Opt-out HIV testing: an ethical analysis of women's reproductive rights. Nurs Ethics. 2011 Sep;18(5):73442. PMID:21642334

27. Bulman D, Mathews M, Parsons K, O'Byrne N. HIV testing in pregnancy: Using women's voices to inform policy. Women Birth 2013; 26(1): e37-40.

28. Nyuzaghl J, Ohene S, Odoi-Agyarko K. Acceptability of routine offer of HIV testing (opt-out approach) among pregnant wom- en in the Wa municipality. Ghana Med J. 2011 Mar;45(1):10-5. PMID:21572819

29. Antiretroviral drugs for treating pregnant women and preventing HIV infection in infants. Recommendations for a public health approach. Geneva: World Health Organization; 2010 (http://www.who.int/hiv/pub/mtct/arv_guidelines_mtct. pdf?ua $=1$, accessed 8 June 2014).

30. Both JM, van Roosmalen J. The impact of Prevention of Mother to Child Transmission (preventing mother to child transmission) programmes on maternal health care in resourcepoor settings: looking beyond the preventing mother to child transmission programme-a systematic review. BJOG. 2010;117(12):1444-50. PMID:20937071 